\title{
Investigating the Impact of Contrasting Paradigms of Knowledge on the Emancipatory Aims of Gallery Programmes for Young People
}

\section{Esther Sayers}

\section{Abstract}

Within an emerging philosophy of contemporary gallery education, new pedagogies are required to meet the demands of looking at art, with increasingly varied constituent groups. Strategies that aim to empower young learners come from an ideological framework in which knowledge is negotiated and local significances are produced conversationally by learners and facilitators. Tension exists between the ideological position and the role of the gallery as 'expert': this conflict creates ambivalence towards the learner. The discourse of the 'expert' and the discourse of 'local negotiation' employ different pedagogic strategies, creating tension in the ways in which knowledge is reproduced for the visitor and participant. This article explores interrogatory pilot work with young people at Tate Modern. I use a hermeneutical approach to explore the interpretive roles of facilitator and participant when language-based strategies are used to look at art. This research aims to construct a pedagogy that enables young people to learn about art in ways that take account of their situation as learners.

\section{Keywords}

gallery, learning, young people, emancipation, hermeneutics, pedagogy 
Introduction

This article explores the production of knowledge at contemporary, publicly funded, collection-based galleries. It examines the different interpretative strategies used by curators, visitors, facilitators and participants, and the challenges faced by young people's programmers who strive to make the institution more welcoming to new audiences.

Recent research, policy and funding has promoted opportunities for young people to access culture in order to engage them in learning, fulfil their potential and enable their full participation in society (Feixa et al. 2011). The inclusion agenda and arts for all initiatives have led towards approaches to learning that aim to empower young people or 'contribute to the undoing of privilege' (Addison 2008). The twenty-first century museum continually aims to diversify audiences, promoting opportunities for everyone to enjoy art (Matarasso 2005, 7). This article explores some pedagogical inconsistencies in the way that the gallery approaches new and established audiences. It points towards new pedagogies and calls for a rethink of current ideas about equality and what we need to do in order to achieve it.

Contemporary approaches to gallery education have emerged over the past 25 years. There is a long history of school groups visiting museums (Hein 1998; Hooper-Greenhill 2007; Selwood et al. 1994), but programmes that are specifically for young people over 15 years of age visiting the gallery independently are relatively new. Since 1994 Tate Liverpool has pioneered new approaches to working with young people through the Young Tate programme. Raw Canvas was established at Tate Modern in 1999 and was informed by the structure, working method and values of Young Tate. Whilst many similarities remain, each programme is designed to respond to the local audience and, as a result, programming at each site is developed in differing ways.

Research has found that young people stop visiting cultural venues at around 14 years of age (Harland \& Kinder 1999). Raw Canvas is for15-23 year-olds who come to the gallery outside of school hours. These younger visitors are not accompanied by a family member or on a school trip, but come by themselves or with their friends. The overarching aim is to create young cultural consumers from diverse backgrounds and in so doing to foster a lifelong interest in art in order to change the demographic of adult gallery visitors in the future.

Galleries are active places; culture is available to the public, art works are conserved and displayed and knowledge is produced. A variety of knowledge is generated: art historical, conservationist, cultural, institutional, knowledge about audiences, knowledge about learning and socio-cultural knowledge. In this article I focus on knowledge about art and the tension between the gallery's role as expert and as a site for empowerment. I will discuss two distinct types of knowledge that are produced at the gallery and the divergent pedagogic strategies that create tension in the ways in which knowledge is 'produced' or 'reproduced' for the visitor and for the participant. I will explore the ways in which contrasting attitudes towards interpretation produce problems for the aims of young people's programmes.

The production of knowledge at the gallery Galleries and art museums have many functions. Some are iconic and some focus on edification by participating in the life of their local community. They are all, at times, scholarly, social, entertaining and educational. When museums were first opened to the public their learning aims were central to the cultural offer that was made. By the 1920s the learning aims had been sidelined in favour of conservation and preservation of the art works in their care. In recent years the learning agenda has once again become relatively central to cultural organisations. Accompanying this development is an increased imperative to understand and negotiate the scholarly and public roles of the museum. Hein $(1998,3)$ asserts that 'education [is] a crucial museum function', although HooperGreenhill $(1991,25)$ points out that whilst 'education had been the prime function of the museum' during the nineteenth century, 'by the 1920s this 
conviction ... was under attack'. At this time curators became more interested in accumulating collections and from then on providing a service to the museum user was not considered to be the primary function. 'Trustees, government, funding bodies and sponsors [will] each have their own view of the status and purpose of the gallery, denying any notion of the gallery as a "neutral" space' (Selwood etal., 1994).

In contemporary gallery education youth programmes have attempted to engage disenfranchised and uninterested young people. The strategies used challenge the orthodoxy of canonical knowledge and uphold inclusive ideologies where all workshop participants are invited to participate in the production of meaning. When a viewer encounters an artwork and tries to understand it, making meaning is the primary goal (Hooper-Greenhill 2000a; 2000b, 136). Although the learner and the curator are both engaged in a search for meaning, two fundamentally different approaches can be observed. Some gallery activities are governed by an approach to learning which involves a search for 'objective truth', whilst others are characterised by an approach in which 'local significance' is negotiated by participants and is considered to be more important than arriving at a fixed meaning or 'truth' about a work.

The emancipatory function of youth programmes places great importance on the potential of meaning making as a strategy for giving power to the disenfranchised individual. Before the 1832 Reform Act it was thought that only the upper classes had the sensibility to appreciate art (Selwood et al.1994). Indeed, the general public were only allowed into museums from the mid nineteenth century. Since then there has been much support for the idea that culture has an improving influence on people's lives. As such, government and philanthropists have gone to great lengths to ensure that cultural learning is available to all sections of society. Emancipatory ideologies argue that learning to interpret the visual and to make meaning from the world around is a vital part of person formation. As Mieke Bal asserts, the interpretive agent plays an important part in the process of meaning making. She talks about a model of semiotics in which the viewer plays an integral role: semiology 'is centrally concerned with reception' (Bal \& Bryson 1991, 184).

Barthes $(1977,147)$ asserts that an image or text does not possess an essential meaning: 'to give a text an Author is to impose a limit on that text, to furnish it with a final signified, to close the writing'. Although the artist/author has an intention, it is the reader or viewer who creates a proliferation of meanings around the work: 'The reader who reads the text brings to it other voices and reads into it textual material which transforms this area of meaning far beyond the author's intention' (Olsen, 1990). Or as Spivak (1976) asserts: 'The text belongs to language and not to the sovereign and generating author.' Therefore, what the viewer brings to the work will play a significant role in any readings that are made. It follows that if you introduce more people to art with a range of different backgrounds then you will get a plurality of readings. Stuart Hall elaborates on the theoretical context of audience studies. He rejects a linear model for the transmission of meaning from author to audience and sets up the idea of two parallel processes working simultaneously, encoding and decoding (Rose 2007): "the moments of "encoding" and "decoding" though only "relatively autonomous" in relation to the communicative process as a whole are determinate moments' (Hall 1980). This idea of plurality is an important precept for group work in which participants are discussing meaning in art works. Different interpretations are made and with them an acknowledgement of different viewpoints; it is up to the facilitator to summarise by repeating the range of views back to the group. And in order to establish a pool of possibilities that are relevant to all the interpretive agents, a peer-to-peer approach to discussion is particularly valuable.

When Tate Modern opened in 2000 it took an approach to collection displays that was thematic rather than chronological as had been traditional in collection-based art museums. At that time the learning team were very much involved in thinking about new audiences for art.
411

Esther Sayers 
In this context the thematic hang was helpful because it allowed for discussions to take place in the gallery that referred to 'old' and 'new' works simultaneously. The context provided opportunities for discussions that focused on the process and the art object without the need to begin every discussion with the historical context of the work. Whilst this approach does not follow a traditional, academic approach to looking at art, the aim was to engage new audiences and for that the non-chronological display created a productive site for discussion. Toby Jackson, Head of Interpretation and Education from 1999 to 2005, asked 'What does it mean to be in a gallery space and not a classroom? What kinds of interaction are possible here? (Jackson, talking to the author on 9 February 2009). The public nature of the context was very different from a school, college or university. The number of visitors far exceeded the gallery's expectations and new programmes had to be created that could cater for large numbers. With the opening of Tate Modern came a new environment for viewing modern and contemporary art, a place that was popular and untraditional. As Jackson states:

we had to turn around the usual model of the museum artefact being received by the public. It was a huge departure from the idea of the compliant, uneducated public who would be given meaning by the 'experts' at the gallery. Enabling multiple voices to speak about the art was an important feature and with that the primacy of the non-expert voice. One of the key concepts that defined the department was about'giving authority to those who have none.' (Jacob 2000)

In her paper 'Competing for an audience: entertainment vs. education', Jacob asked: 'Who is given authority to speak in the space of the museum? Everyone has a "voice" and, everyone should be heard and be given the opportunity to be challenged.'

The key to building new audiences who feel ownership of the art is to enable an interaction to take place in the gallery space that is meaningful to them.

\section{Contrasting paradigms of knowledge}

The scholarly and emancipatory paradigms of knowledge at work in the gallery determine attitudes towards the art and the programmes that seek to illuminate it for the public. The two models have different dynamics. One is driven by a scholarly elitism, which has been upheld within the gallery since its inception in the late 1800s. The other is egalitarian, philanthropic and aimed at those who do not have access. The scholarly approach embraces the fact that some people have a priori knowledge allowing them intellectual access to exhibitions as the curator intended. This knowledge is that of the highly educated subject. The art works and the way they are displayed serve to reconfirm the educated subject's position. Such people possess, in Bourdieu's terminology 'cultural capital'. 'According to Bourdieu, works of art can have meaning only for those with sufficient "cultural capital" at their disposal' (Kockel 2000). 'True distinction, besides, always affects to address only distinguished persons who know the same customs, and it does not "explain"" (Bourdieu 1979, 499).

The egalitarian approach to knowledge asserts that culture is for everyone and that anyone can have a meaningful exchange with cultural objects if the circumstances are managed effectively. It could be argued that this approach implies an initial deficit, a lack of culture that needs to be corrected, but equally one could argue that this approach presupposes an idea of equality of intelligences (Rancière 2010). Gallery education departments attempt to be non-didactic, to be open and inclusive. Located within a constructivist epistemology, they emphasise the creative activity of the learner above the status of the knowledge.

When we think about the process of looking at art, conflict exists between scholarly strategies that are concerned with 'cultural reproduction' and egalitarian strategies that are concerned with 'cultural conversation' or 'negotiated interpretation'. This conflict is explicated in the debate about 'reproduction' that defines the difference between conservative and moderate hermeneutics as described by 
Gallagher (1992). Hermeneutics is the study of interpretation and meaning. It accepts that experience is vital to understanding, although which experiences are valid is the subject of debate. Educational strategies in the gallery have established an approach to learning that uses the learner's lived-experience as an interpretive tool. In the debate about reproduction, Gallagher, Hirsch and Gadamer argue about the importance of 'truth' in interpretation: 'Given the prejudicial nature of interpretation, is it ever possible to achieve an objectively valid interpretation?' (Gallagher 1992,12).

In this debate Gallagher cites the conservative hermeneutics of Hirsch and the moderate hermeneutics of Gadamer. Starting from the assumption that any interpretation is biased in some way, this debate acknowledges that an interpretation can be constrained by the prejudices of the author. A key question in the debate is 'Is the interpretation correct?' The conservative hermeneutics of Hirsch are concerned that the interpretation must be objective (not arbitrary). Gadamer argues that it is not possible to make an entirely objective interpretation, in that the interpreter plays an intrinsic part in the meaning that is made. Hirsch argues that meaning is fixed within the object and that we should not confuse 'meaning' with 'significance'. There is a difference between 'the meaning of a text' (which is unchanging) and 'the meaning of a text to us today' [its significance] (which changes) (Hirsch 1965, 498). So Hirsch makes a distinction between meaning that is inherent to an artwork, for example, and how it is made meaningful in the way we interpret. Educational activities are not intended to change the 'meaning' of an artwork, but they are intended to make it meaningful to the interpreter. If, as Gadamer insists, new meaning is produced, then what happens to it? Does a reservoir of new meaning about an artwork begin to grow?

The conservative idea of the interpreter corresponds to Hooper-Greenhill's 'knowing subjects' in her model of nineteenth-century visitors who engaged in 'learning at a glance' and could assimilate knowledge from an exhibition through their already constituted position as 'knowing subjects' with the appropriate cultural capital. $(2007,190)$. In this model the visitor already has a high level of knowledge about art, they can 'enter the conversation' at a similar point as the Exhibition Curator. In this instance meaning is fixed, it exists within the canon and is agreed by both parties. When the meaning that is reached corresponds to canonical knowledge about the work, then the interpreter's subjectivity remains 'concealed' and the interpretation can be described as objective. Whilst there have been remarkable exceptions, the overriding orthodoxy of exhibitions in national, collectionbased galleries reflects Hirsch's conservative hermeneutic insisting that there is an essential truth within the art work that viewers should return to in order to make a valid interpretation. Gadamer disagrees with Hirsch: he asserts that meaning is not reproduced by the interpreter but, rather, new meaning is produced. Gadamer supposes that 'every attempt at reproduction involves a production of new meaning, and thus, strict reproduction is not possible' (Gallagher 1992, 15).

The debate around 'reproduction' in contemporary hermeneutic thought sheds light on an area of gallery education pedagogy where confusion exists. Some gallery activities are governed by a conservative approach to learning in which participants search for a specific meaning and others are characterised by a moderate approach in which 'local significance' is considered to be more important. Often the learning for participants who are more familiar and confident with art is structured in a conservative way and moderate strategies are used for those who are less familiar and less confident. For example, during a workshop the facilitator is constantly making decisions about how to engage participants in the work. If we imagine that there is a scale where the artwork exists at one end, with the viewer at the other, then the facilitator moves in between. With a confident participant, the facilitator, metaphorically, stays close to the artwork and through questioning draws the participant out of their subjectivity and 'into' the work. With a more reluctant learner, the dialogue is more conversational and
413

Esther Sayers 
stays closer to the viewer. Here the facilitator looks for 'hooks' to emerge between their subjective experience and the artwork. The concern for the 'status' of the learner in conservative hermeneutic thought sits uneasily with gallery education strategies that attempt to engage disenfranchised and disinterested young people. In the conservative model Betti (1957) placed importance on 'the subjectivity of the interpreter and [the interpreter's] awareness of the preconditions of his ability to understand in a manner adequate to the subject-matter' (see Gallagher 1992).

His insistence on 'preconditions' for understanding mean that only some people have the required ability to access certain material. This notion sits uncomfortably with gallery approaches to learning that aim to offer equality of access regardless of the learners' status or level of education.

All visitors use previous knowledge to make sense of artwork: for the 'educated' audience familiar with art historical scholarship, this 'schema' corresponds to the expert voice and reproduces the meaning written about the work. Scholarly knowledge is conservative, didactic, canonical; it can be found in text panels and exhibition design where the viewer is informed about the work by an expert. Exhibition displays are authored and the learner is required to break out of their historical or cultural situation to appreciate the display as the author intended. In this exchange objective 'truth' is asserted.

On the other hand, emancipatory knowledge is egalitarian; it aims to create access for the maximum number of people. It is such negotiated knowledge that tends to drive learning programmes. Here the 'truth' about the work is not predetermined: the interpretation of the work is arrived at by the individual, according to their own knowledge and experience. The learner participates with the author/artist in putting together meaning: no objective 'truth' is sought. In the elitist view, the 'truth' about the work already exists and is reproduced by the visitor who is able to comprehend it. An alternative view is that one, singular 'truth' cannot be reproduced by the visitor because each person brings a different set of prior experiences. The viewer generates knowledge through a process of negotiation. The knowledge produced is unique in each case and is subject to change, as such 'knowing' is an active state developed as a result of lived experience. In this view it is essential that young people are provided with the skills to form their own knowledge and understanding of the world.

Recalling the debate about 'reproduction', the validity of the question 'Is the interpretation correct?' is important. The school system, in its more traditional didactic form, teaches young people to accede to the authority of experts. This conditioning, I would argue, is counterproductive when attempting to empower young people to make decisions and formulate their own opinions. Peer-led pedagogies aim to disrupt the hierarchies between teacher and pupil, the 'expert' and the 'learner' and, instead, create a 'community of learners' in order to provide young people with the skills they need to take part in debate and to get their opinions heard.

I will now discuss a workshop in which the production of 'local' meaning occurs and where new pedagogic strategies have been developed. We are all experts was a series of workshops that took place at Tate Modern on Friday nights during the summer of 2009. The programme was created by Raw Canvas peerleaders in collaboration with artists Emma Hart and Melanie Stidolph. It was an attempt to construct a new pedagogy, a new approach: one that acknowledged the power of the expert voice to an underconfident audience and one that sought to challenge the whole notion of the 'expert' head on.

To enable many voices to be heard speaking about art it was important that the events were well attended by a varied group of interested parties. To this end multiple marketing approaches were used to reach the broadest range of young people demographically, educationally and culturally. Prior to each workshop Raw Canvas peer-leaders spent two hours handing out flyers to the young public inside the gallery and outside in the surrounding area. 


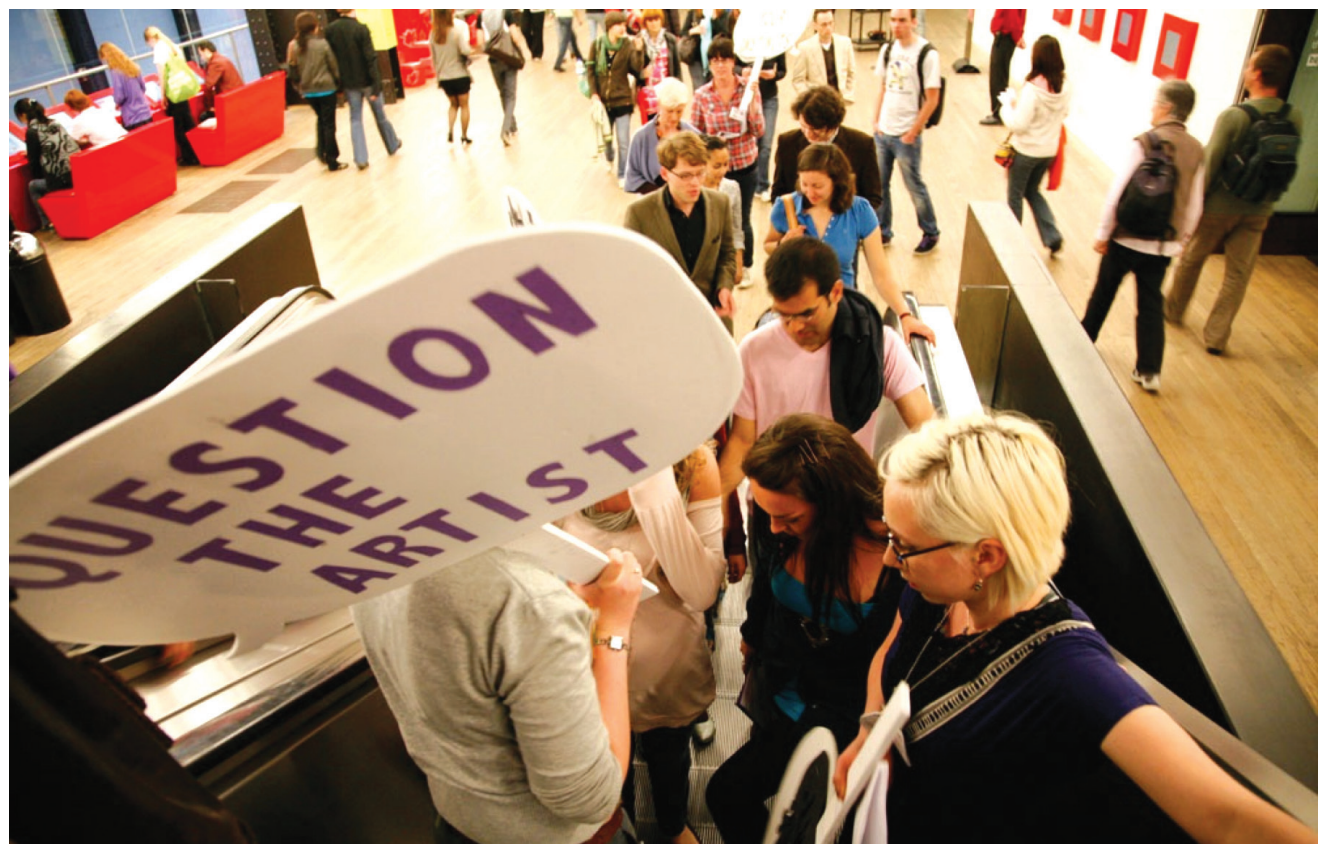

There was also event information in the Tate events booklet, on the website, in the Raw Canvas newsletter, by email, on Facebook, through the blog (http://weareallexperts.wordpress.com/) and by word of mouth. The workshops attracted higher than expected numbers of people. The maximum group size for an effective discussion in the gallery is 20 , but the highly visible nature of the event attracted many passers-by as well: on three occasions there were over 40 participants. The workshops were popular with adult visitors as well as young audiences. The peer-leaders decided to permit adults to take part in the interests of having a variety of experiences enabling pluralist and multi-faceted interpretations to take place in an open, public-facing event without restrictions. Although considerable effort had been made to attract a broad range of participants, the workshops were mainly attended by young people in further or higher education; they did, however, attract at least two-thirds of young people from non-art subjects. Perhaps because of their stated aim to be non-canonical and not to have a traditionally expert voice, they failed to attract a specialist audience. This is interesting in thinking about which are the appropriate pedagogi- cal approaches for programmes that aim to emancipate young people. It would seem that young people whose knowledge corresponds to the canon have less interest in events that aim to emancipate and more interest in didactic events whose purpose is to contribute to specialist subject knowledge. Equally, the workshops failed to attract a novice audience.

By holding an open discussion in public the aim was to challenge the canonical voice and conventional notions of who has the right to speak about art, and whose knowledge is valid in making interpretations of art. The Raw Canvas peer-leaders produced placards in the shape of speech balloons. On the placards were questions like 'love it or hate it?' and instructions like 'get the message' and 'trust your instincts', or the beginning of a possible response 'this reminds me of'. These were intended to urge the public to take part and to stake out some space in the gallery for the discussion to take place. The placards drew attention to the event but they also had the surprising effect of lending legitimacy to the group by giving them a presence in the gallery. One peer-leader, Katie Schwab, commented: 'Raw Canvas activities always seem inherently antagonistic to the
415

Esther Sayers
This page:

Figure 1

We are all experts, June 2009. Led by India Harvey (right front), the group ascends to the galleries at Tate Modern. Photo credit: James Deavin 
institution - whether it's through waving placards, or playing music, or going to the gallery in fancy-dress.'

Entitling the series We are all experts was intended to purposefully avoid one singular voice being heard over and above the others. The approach of the facilitators was crucial to avoid being identified as the expert voice: the facilitators were not leading the group from the front, but instead positioned themselves within the group. A peer-led pedagogy was used for many reasons: to make participants feel at ease, to enhance the social nature of the session and the ensuing discussion, to provide a fresh perspective on modern and contemporary art, to avoid a traditional 'expert' voice which could be considered off-putting. The approach meant that instructions to participants were issued by their peers and, as such, were less authoritative and came across as 'suggestion' more than 'instruction'. Instead of using a didactic pedagogy, the artist educator and facilitators listened carefully to the discussion and interjected additional questions or extra 'nuggets' of information about an artist, their work or the context in which it was made. This helped to steer the discussion and ensure that personal interpretations did not become too relativist in nature.

By inviting non-art specialist friends and acquaintances, Raw Canvas wanted their speakers to use the 'knowledges' that young people already possess. They brought their prior knowledge into the interpretations that they made. Here the pedagogy was about the primacy of the non-expert voice when making interpretations about art. It was also a kind of 'social' pedagogy that centred on the relationship of group members with each other, group members with the facilitators (including the peer-leaders) as well as between each individual and the art object. The interpretations were the result of complex dialogue between these agents. The underlying aim for the project came from Tate's imperative to encourage 'cultural omnivorousness' (Bennett et al. 2009) in young people and to encourage a new and more diverse generation of confident, cultural consumers who can make their own judgements: 'Contemporary cultural advantage is pursued not through cultivating exclusive forms - of snobbishness or modernist abstraction - but through the capacity to link, bridge, and span diverse and proliferating worlds' (Bennett etal. 2009).

The series came from a desire to reject the emancipatory aims of youth programmes by creating 'enthusiastic amateurs' (Hall \& Meecham 2003) rather than to be 'educational' and 'good for' young people. Claire Bishop (2007), in writing about relational aesthetics, has distinguished art projects which make space for critical thinking and allow the audience to be driven by their own interests and 'passion for knowledge'; they are projects which often use an educational framework. She instances Thomas Hirschorn, who organised $24 \mathrm{hr}$ Foucault at the Palais de Tokyo, Paris in 2004. Rather than producing a straight academic conference, Hirschorn took an approach that was chaotic and multidisciplinary. It is significant that he operates from a position of amateur enthusiast rather than informed professional. He said: 'Concerning Foucault, I don't understand his philosophy, and I think that I don't have to understand his philosophy in general, I am not a connoisseur. I am not a specialist; I am not a theoretician ... I want to work as a fan'. The projects cited by Bishop in her article 'rethink the possibility of non-alienated learning through the lessons of artistic sensibility'; this thinking informed the idea for We are all experts.

An 'expert' was invited to share their take on the work - not an art expert but an 'inspirational peer'- the same age as the peer-leaders and invited by them. They were someone known to one of the group and whom they had found to be inspirational in some way. They were asked to select a work in advance and then to give a fiveminute talk that offered their viewpoint of that work and provided a personal context and threads of new meaning to form the starting point for discussion. This approach created an open and speculative forum in which participants felt at ease to offer their own ideas. The discussion was not without guidance, as an artist educator was always present to occasionally steer the conversation or seek clarification if 


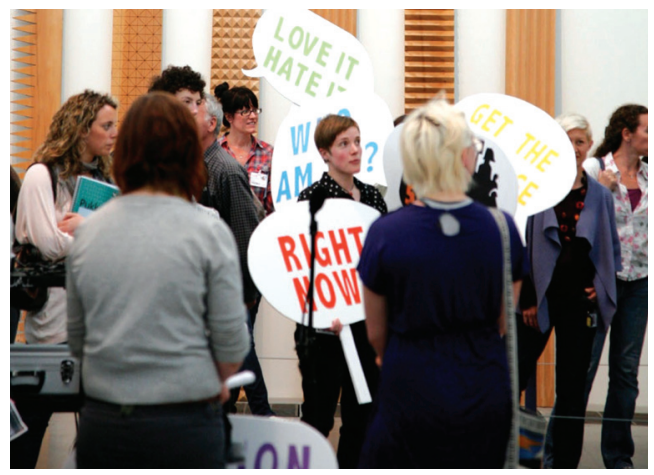

the group began to make unsubstantiated claims for the work. Such facilitation was carefully executed so as not to introduce an expert voice that disturbed the very purpose of the group. Greater confidence was apparent towards the end of the workshop when more people were prepared to be heard voicing their own ideas rather than listening to one person or waiting for an expert to speak.

In Figure 3 the invited 'expert' talked about her experiences of growing up in Estonia in the 1980s during occupation by the Soviet Union, when it was 'under big great Russia'. She talked about going to school in Estonia before the country achieved independence in 1991 and she identified 'Uncle Lenin and Uncle Stalin, as we had to call them' in the posters on the walls, she described how 'they rewrote the history books to say how great they were'. This personal viewpoint of Estonian history had the audience captivated, focused, the work began to open up to them, there were many questions and the speaker went on to share her reading of the work, other people 'chipped-in' and gradually an explanation of the work was arrived at which was meaningful to those involved in the discussion. It was not spurious conjecture, but it did not correspond to the text panel in the gallery. For the group the work had new significance, it had become meaningful. They went around the gallery with different speakers who offered insights and or expertise that opened up an alternative point of view. One of the peer-leaders, Chloe Cooper, commented:

I've previously thought quite critically about the

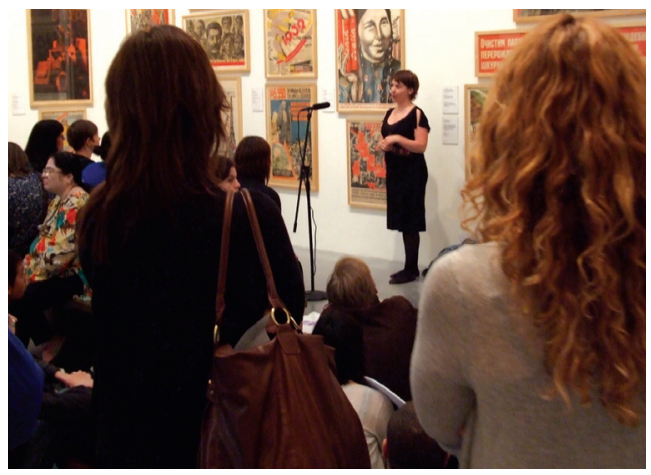

'expert' role that we undertook as itactually reinforced the binary between expertand layperson instead of subverting it. The five-minute talk format sometimes eliminated dialogue but this is a great example of when it worked as we had intended.

\section{Divergent pedagogies}

A number of pedagogical issues emerge out of Raw Canvas activities: the most striking is the rejection of strategies that are strictly about the object and that could be associated with a didactic, canonical approach. Instead, the pedagogy of relations 'between' participants and 'around' art objects is emphasised. This relational pedagogic approach is more in keeping with current trends in art practice in which the role of participant is transformed from viewer to collaborator. By attending to the relations between participants and the art object in the We are all experts workshops, the facilitators' task was complex: they kept discussions conversational in order to encourage participation and they listened carefully and dropped in questions or 'nuggets' of additional information about the artist, the work or the context in which it had been made. One aspect of this pedagogic approach was the decision to stand back and say nothing at times. In Raw Canvas sessions an experienced artist educator works closely with peer-leaders to devise workshop activities. The activities are designed to allow participants to be social, to be relaxed and to be themselves in order to elicit personal and meaningful responses. To achieve this, artists and peer-leaders asked open questions that projected possible meanings onto
417

Esther Sayers
This page:

Figure 2

We are all experts, June 2009. Photo credit: James Deavin

Figure 3 We are all experts, June 2009. Photo credit: Esther Sayers 
the work, or led towards preconceived lines of enquiry. Conversationally ideas, comments and interjections from the leaders were left unresolved in order that the participants could appropriate them and make meaning of their own. There was no pressure for any individual to respond to one particular question, instead the sociable nature of the group fostered an exchange of ideas.

In Youth Programmes at Tate Modern participants formulate opinions of the work, they also discover their own areas of interest and these personal points of interest are developed into proposals for events and activities. This creates an inclusive pedagogy where, rather than providing activities that are for young people, the events programme is designed and delivered with young people. This approach is pedagogically distinct from the elitist model where the aim is to transmit knowledge or to enlighten the learner.

At the end of the annual peer-leaders training course all participants complete a project. The task is to design an event to take place at the gallery; they must nominate a target audience and an art work that the event will refer to. They must take account of the specificity of Tate Modern as a venue. All proposals are presented at the end of the training course and selected ones are re-presented to curators and to other peer-leaders after the course, at the Raw Canvas programming meetings where they are approved, modified or occasionally rejected. This loosely constituted group validates (or not) by providing funding and support to fulfil some ideas and not others. There are no specific criteria here, but the artwork itself provides an anchor-point against which the idea is tested. A successful proposal is one that remains 'true' to the work whilst also providing a new perspective on modern and contemporary art. Mixing the intention of the work with a new cultural form, rapping about Picasso for example, is seen as a successful idea. Here a productive relationship is formed between the cultural forms of painting and rapping, which facilitates a dialogue between Picasso and the contemporary world of the interpreter. 'Truth' here is not

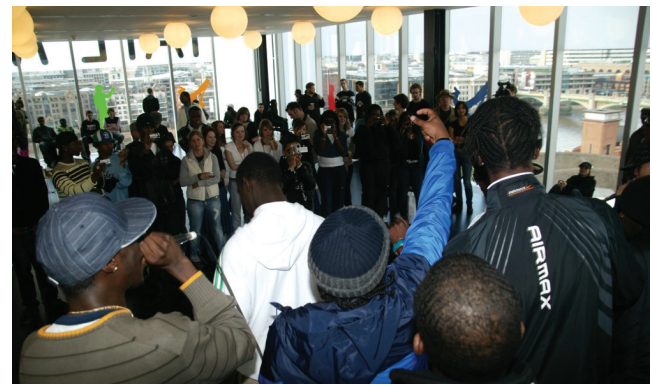

universal 'truth', but is limited to that which has local significance for the viewer.

Raw Canvas has always been about giving power to young people to create and deliver their own activities, with the aim of breaking down the barriers that disconnect young people from modern and contemporary art. Raw Canvas invites young people to the gallery to extend their experience of looking at art into making, performance and discussion. It is important that they feel ownership of the public space of the gallery as the primary concern for the programme has been about building young audiences for art. This has required the culture of the institution to change in relation to young visitors, and has relied on the ability of staff at all levels to be respectful towards young people and to support them in the delivery of their programmes. In order to attract 15-23-yearolds, new pedagogies have been developed that are not didactic but conversational, peer-led and social. The peer-to-peer discussion means that language that is familiar to young people is used, and often the workshop activities are delivered with less formality than if an artist educator were leading. For example, one activity can flow into the next, the tasks are not separated and targets are not explained at the start, but emerge through the process; young people enjoy the open-ended feeling that apparently 'random' activities provide. Such learnercentred and dialogic approaches have proved to be relevant and attractive to new audiences.

Hall \& Meecham talk about research that 'reveals the importance of the viewer's prior knowledge in meaning making'. They describe pupils incorporating the language acquired during maths lessons to the abstractions of a 
Fernand Leger painting: 'The pupils quickly incorporated what they knew into what they saw thus abandoning any notion of the reified art work, a process that is still considered heretical in some quarters' (Hall \& Meecham $2003,154)$. Here 'young pupils have a way into the artwork from their own experience'. This provides an example of negotiated, local meaning and the use of foreknowledge or schema in making an interpretation. Through this example of young people using their knowledge we can see that even very young children can engage in complex assimilations of knowing and seeing when encouraged by sensitive teaching in the gallery. A successful facilitator can acknowledge the learner's position in relation to the art and create challenging opportunities for learning.

Charman \& Ross explore interpretation with a group of teachers at the Tate Modern Summer Institute. It is clear that some difficulties emerge for teachers in the acceptance of a non-canonical, non-authoritative voice:

The notion that works of contemporary visual art can have multiple interpretations which are created by the viewer is the alternative to a traditional approach to understanding an art work which emphasises the transmission of meaning from teacher to pupil. (Charman \& Ross 2006, 31)

The concept of multiple interpretations is treated with suspicion by some because of anxiety about the possibility of a viewer making meanings that are not intended by the artist:

At the beginning of the week the group exhibited an enthusiasm to identify a single authoritative voice to deliver what was considered the definitive meaning of the work. Most often this 'true' voice was taken to be the artist's intention. If this strategy failed, another authoritative voice was substituted, mostcommonly that of the arthistorian. (Charman \& Ross 2006, 32)

This action research project demonstrates the tension between the two paradigms of knowledge that I have highlighted: the teachers want to accede to the authority of experts in just the way that the Raw Canvas peer-leaders have noted when they begin to plan the We are all experts series. As Hall \& Meecham point out, encouraging people to formulate their own understanding, and in so doing 'abandoning the notion of the reified art work', is still considered unacceptable by some. New pedagogies are responding to the viewer's repositioning as a participant in the meaning making process (Bal \& Bryson 2001). However, whilst 'alternative frameworks for interpretation are sought' (Hall \& Meecham 2003, 155), the production of meaning cannot lead to speculation that bears no relation to the specific history or context of the art work. A balance must be sought in which the canonical knowledge informs, rather than overrides, the individual's 'locally significant' reading of the work.

\section{The challenges for young peoples"}

\section{programmes}

Whilst museums have been 'open' for 150 years, recent research suggests that they are still mainly attended by the 'highly educated' middle class and the elite (Bennett etal. 2009). The difficulties for contemporary youth programmes stem from issues that arose during the mid nineteenth century when museums and galleries were newly constructed as social places in which 'the working class-provided they dressed nicely and curbed any tendency towards unseemly conduct - might be exposed to the improving influence of the middle classes' (Bennett 1995). In Foucauldian terms, 'the instruments of government' in the nineteenth century were aimed at bringing about acceptable norms of conduct, not by corporal punishment but by manipulating behaviour through specifically built environments (Foucault 1977, 95).

Museums have been described as the kinds of regulatory environment that Foucault talks about. Introducing new audiences creates a problem: do you teach the newcomers how to behave 'correctly' or does the institution adjust its idea of appropriate conduct? The activities of the gallery have attempted to do both. This has made them pedagogically divergent by occupying elitist and populist positions simultaneously,
419

Esther Sayers

Opposite page:

Figure 4

Spoken word event at The Long

Weekend, Tate Modern, 2006.

Photo credit:

Ivo Gormley 
creating tension in the way that the gallery approaches the audience. It is the space between the poles of elite and popular taste that offer the best opportunities for interesting and active projects, where the purpose and potential of the gallery is negotiated by the project participants and facilitators. We can still see the drive towards 'self-improvement' for the populace today in the desire to invite new audiences from 'hard to reach' groups who do not normally engage with these kinds of cultural activities. Their attendance is prized but it is also monitored and restricted by institutional rules and codes of conduct. Whilst there has been a shift of perception towards young people at front of house, it is often the learner who develops as a result of their experience, whilst the museum remains largely unchanged. Despite considerable effort to welcome a diversity of young people, what emerges is ambivalence towards the new audience, who are simultaneously welcomed and controlled. The problem for young people's programmes relates to the divergent pedagogies that I have outlined and their inherent and conflicting ideas about 'equality'.

Rancière makes a forceful intervention into this ambivalence through the axiom of the equality of intelligence (Bingham \& Biesta 2010, 44). Youth programmes were grounded on an idea of equality where 'young people can be heard speaking about art' (Raw Canvas aims, 2001): an aim which makes the visitor's own experience, prior knowledge or schema into a contingent part of their response to art. In this view everyone's opinion is equal: 'your opinion goes here' (Raw Canvas publicity, 2003). When localised within youth programmes, this was effective. However, once the youth programme became more integrated into Tate, it began to affect the culture of the institution. At this point it was evident that this equality was ideological and did not afford greater power to young people in relation to the institution.

The objective is to make Tate Modern a more diverse place to reflect the diversity of the community local to the gallery. This means that the gallery wants new audiences to become part of the 'cultural conversation'. In contrast, the objective of the youth programme is to change the 'cultural conversation' to enable young people's intelligences to speak. Researchers Galloway \& Stanley (2004) from Warwick University found that Raw Canvas was achieving its objectives in providing a peer-led programme where young people's ideas and opinions can be heard, and creating a lively forum through which young people could access modern and contemporary art. However, the evaluation also found that 'the aspiration of the youth programme to advise and work with Tate on issues concerning young people as users of the gallery remains unfulfilled'.

The production of meaning during educational activities at the gallery is not intended to contest or alter the art history written about the work; there is no explicit intention to challenge art history per se. However, knowledge takes many forms: the aim of the learning activities that I have shown is to create a meaningful exchange between an artwork and a young person. My intention is to highlight the conflict between conservative and moderate approaches to interpretation. This is in order better to understand how that conflict creates a knowledge hierarchy affecting the relationship between departments and the opportunities for young people's voices to be heard speaking about art. I am looking for a new pedagogy that disrupts the hierarchical divisions within the art museum that place scholarly programmes and more populist ones at opposite ends of the scale. The aim of my research is to construct a new pedagogy for the twenty-first century art museum that centres on personalised learning and is relevant to young people. Such pedagogies need to remain vigilant and responsive to change in order to maintain their relevance. The intention is to shed light on how learners are constructed through peer-led gallery experiences in order to create a museum that is still relevant and meaningful to young people 20 years from now.

I have looked at parallel forms of interpretation and I have focused on those that take account of equality, learning and accessibility. I have reached an understanding of a number of 
different pedagogical practices. However there are still crucial questions that remain to be addressed. How do we understand these processes of emancipation? How emancipatory are they? Are they paternalistic? As the role of the 'viewer' is transformed into 'participant' and then 'collaborator', is it time for learning projects to embrace a more relational dialectic between 'producers' and 'users' of culture?

Esther Sayers was Curator for Young People's Programmes at Tate Modern from 2002-2011. She received her MA in Fine Art from Staffordshire University in 1995 and BA (Hons) in 3D Design from Brighton University in 1993. She is currently studying for a $\mathrm{PhD}$ in Education at Goldsmiths, focusing on the institutional and personal impact of gallery activities for new audiences. Esther's professional experience began by leading workshops in schools, youth clubs and galleries. She has been a gallery educator at Tate Liverpool, Tate Modern and Whitechapel Gallery, lecturer at Loughborough and Staffordshire Universities and Special Projects Coordinator at Camden Arts Centre. Esther's art work has been written about by Marsha Meskimmon for publication in Make magazine and through Scarlet Press. Email: esther.sayers@gmail.com

\section{References}

Addison, N. (2008) Agency in gallery and art education, International Journal of Visual Art and Gallery Education, Vol. 22, No. 1, pp. 13-18

Bal, M. \& Bryson, N. (1991) Semiotics and art history, Art Bulletin, Vol. 73, No. 2, pp. 174-208

Bal, M. \& Bryson, N. (2001) Looking in the Art of Viewing. Amsterdam: G+B Art International

Barthes, R. (1977) Image, Music, Text. London: Fontana Press

Bennett, T. (1995) The Birth of the Museum. London: Routledge
Bennett, T., Savage, M., Silva, E., Warde, A., Gayo-Cal, M. \& Wright, D. (2009) Culture, Class, Distinction. London and New York: Routledge

Bingham, C. \& Biesta, G. (2010) Education, Truth, Emancipation. London: Continuum

Bishop, C. (2007) The new masters of liberal arts: artists rewrite the rules of pedagogy, Modern Painters, September, pp. 87-9

Bourdieu, P. (1979) Distinction. London and New York: Routledge

Charman, H. \& Ross, M. (2006) Contemporary art and the role of interpretation: Reflections from Tate Modern's Summer Institute for Teachers, International Journal of Art \& Design Education, Vol. 25, No. 1, pp. 28-38

Feixa, C., Huq, R., Laaksonen, A., Suurpää, L. \& Varbanova, L. (2011) Access of young people to culture, Interarts Foundation (online). Available at: http://ec.europa.eu/youth/pdf/doc1790 en.pdf (accessed February 2011)

Foucault, M. (1977) Discipline and Punish. London: Routledge

Gallagher, S. (1992) Hermeneutics and Education. Albany: State University of New York Press

Galloway, S. \& Stanley, J. (2004) Research Partnership for the Evaluation of Tate Modern's Youth Programme 'Raw Canvas', Interim Report. University of Warwick

Hall, N. \& Meecham, P. (2003) Creative partnerships or more of the same?, in $\mathrm{N}$. Addison \& L. Burgess [Eds] /ssues in Artand Design Teaching. London and New York:

Routledge, pp. 151-7

Hall, S. (1980) Encoding/decoding, in S. Hall \& P. Willis [Eds] Culture, Media, Language. London: Hutchinson, pp. 128-38

Harland, J. \& Kinder, K. [Eds] (1999) Crossing the Line. London: Calouste Gulbenkian Foundation

Hein, G. E. (1998) Learning in the Museum.

London and New York: Routledge
421

Esther Sayers 
Hirsch, E. D. (1965) Truth and method in interpretation, Review of Metaphysics, Vol. 18, No. 3, pp. 488-507

Hooper-Greenhill, E. (1991) Museum and Gallery Education. Leicester: Leicester University Press

Hooper-Greenhill, E. (2000a) Learning in art museums: strategies of interpretation, in $\mathrm{N}$. Horlock [Ed.] Testing the Water. Liverpool: Liverpool University Press and Tate Liverpool, pp. 136-45

Hooper-Greenhill, E. (2000b) Museums and the Interpretation of Visual Culture. London:

Routledge

Hooper-Greenhill, E. (2007) Museums and Education: Purpose, Pedagogy and

Performance. London: Routledge

Jacob, M. J. (2000) Competing for an Audience: Entertainment versus Education. Directors Choice: The Sixth Annual Directors Forum Transcripts. New York: American Federation of Arts

Kockel, U. (2000) Beyond L'amour de l'art, cultural democracy and Europe, in N. Horlock [Ed.] Testing the Water. Liverpool: Liverpool University Press and Tate Gallery Liverpool, pp. 39-47

Matarasso, F. (2005)Artfor Our Sake: The Artistic Importance of Community Arts (online). Available at: http://homepage.mac.com/ matarasso/Menu12.html (accessed 16 January 2008)

Olsen, B. (1990) Roland Barthes: from sign to text, in C. Tilley [Ed.] Reading Material Culture. Oxford: Basil Blackwell, pp. 163-205

Rancière, J. (2010) On ignorant schoolmasters, in C. Bingham \& G. J. J. Biesta, Jacques

Rancière: Education, Truth, Emancipation. London: Continuum, pp. 1-24

Rose, G. (2007) Visual Methodologies. London: Sage
Selwood, S., Clive, S. \& Irving, D. (1994)

Cabinets of Curiosity: Art Gallery Education. London: Art\& Society

Spivak, G. C. (1976) Translator's Preface, in J. Derrida, Of Grammatology. Baltimore: Johns Hopkins University Press, pp. ix-Ixxxvii 